\title{
Injuries among children and youth in farm households: Regional Rural Injury Study-I
}

\author{
S G Gerberich, R W Gibson, L R French, C M Renier, T-Y Lee, W P Carr, J Shutske
}

Regional Injury Prevention Research Center, Division of Environmental and Occupational Health, School of Public

Health, University of Minnesota,

Minneapolis,

Minnesota

S G Gerberich

Regional Injury Prevention Research Center, Division of Environmental and Occupational Health, School of Public

Health, University of Minnesota and

Behavioral Sciences, Medical School,

University of

Minnesota-Duluth and

Divisions of

Environmental and

Occupational Health

and Epidemiology,

School of Public

Health, University of

Minnesota,

Minneapolis

R W Gibson

Division of Chronic

Disease and

Environmental

Epidemiology,

Minnesota

Department of Health,

Minneapolis

L R French

Behavioral Sciences, Medical School,

University of

Minnesota-Duluth,

Duluth, Minnesota

C M Renier

Department of Preventive Medicine and Public Health, College of Medicine, Chungnam National University, Taejon, Korea and

Environmental and Occupational Health, School of Public

Health, University of

Minnesota,

Minneapolis

T-Y Lee

\begin{abstract}
Objectives-The purpose of this effort was to identify the incidence and consequences of both farming and non-farming related injuries and the potential risk factors for farming related injuries among children and youth, aged 0-19 years, who lived in farm households in a large region of the United States.

Methods-Data were collected from randomly selected farm households during 1990. Rates and rate ratios with $95 \%$ confidence intervals were calculated for sociodemographic and exposure variables. Multivariate analyses were conducted, using a priori and backward stepwise logistic regression models.

Results-Within the population of 3939 farm households and 13144 persons, children and youth accounted for $33 \%$. Injury rates for farming and non-farming sources, respectively, were 1683 and 6980 per 100000 persons. Animals (40\%) were the primary sources of the farming operation related injuries; sports/recreation sources $(61 \%)$ were associated primarily with non-farming related injuries. Of the farming and non-farming operation related injury cases, $83 \%$ and $90 \%$, respectively, required some type of health care; moreover, $17 \%$ and $24 \%$, respectively, were restricted from regular activities for one month or more.
\end{abstract}

Through multivariate analyses, important increased rate ratios were observed for operating a tractor, working with dairy cattle, and being male. Increased rate ratios for working with beef cattle, operating a harvester, and living on a farm where there were all terrain vehicles in use, and a decreased rate ratio for living on a farm where there were sheep, appeared suggestive.

Conclusions-Based on the relevant rates, injury consequences, and potential risk factors identified, injuries to children and youth on farms represent a significant problem. Future analytic studies are essential to identify more specific risk factors that can serve as a basis for development of appropriate intervention efforts. Given the population at risk, and the opportunity for intervention in this unique occupational setting, many of these injuries may be readily amenable to prevention efforts.

(Injury Prevention 2001;7:117-122)

Keywords: agriculture; farm; surveillance; risk factors
Mortality and morbidity rates, for agriculture, consistently identify it as one of the most hazardous occupations in the United States. Unlike most occupations, the hazards associated with agriculture affect a broad segment of rural populations, including children and youth. A major barrier to progress in the prevention of agricultural injuries has been a lack of knowledge about the magnitude of the problem and of specific risk factors. ${ }^{1-3}$ Population based, analytic studies are integral to this knowledge and the ultimate development of relevant prevention efforts, but have been limited to this time..$^{3-8}$

Fatality rates identified for agriculture have ranked among the highest across all occupations for many years. In 1998, agriculture accounted for 22 deaths per 100000 workers, compared with four deaths per 100000 workers in all occupations. ${ }^{9}$ Although limited, morbidity data suggest a major problem among farm residents. ${ }^{35} 810-18$ In 1998, an estimated 140000 disabling injuries occurred in agricultural work, accounting for a rate of 4058 per 100000 workers. $^{9}$ While there is some evidence about the magnitude of agricultural related fatality among children and youth, indicating that, between 1990 and 1993 more than 100 were killed in the United States, ${ }^{13}$ there is little information about morbidity and potential risk factors for both morbidity and mortality.

The goals of the present study were to identify the incidence, consequences, and potential risk factors for injuries among children and youth, aged 0-19 years, in a large region of the United States. Both farming and non-farming related injuries were investigated to determine the magnitude of the total injury experience. However, identification of potential risk factors was necessarily limited to agriculturally related injuries because of the diversity of non-farming injuries and the inherent complexity in determining pertinent exposures.

\section{Methods}

To examine the problem of injury among children and youth in farm households, the Regional Rural Injury Study-I (RRIS-I) ${ }^{5}$ cohort database was used. The RRIS-I was a five state population based study, conducted in Minnesota, Wisconsin, North Dakota, South Dakota, and Nebraska for two six month periods during 1990 (1 January to 30 June; 1 July to 31 December). This study used computer assisted telephone interview based injury surveillance that was modeled after the Olmsted Agricultural Trauma Study (OATS) ${ }^{3}$ in which a major injury validation effort was conducted. ${ }^{18}$ 


Division of
Environmental and
Occupational Health,
School of Public
Health, University of
Minnesota,
Minneapolis and
AIDS/STD Prevention
Services Section,
Minnesota Department
of Health
W P Carr
Biosystems in
Agricultural
Engineering
Department,
University of
Minnesota,
Minneapolis
J Shutske
Correspondence and reprint
requests to:
Dr Susan Goodwin
Gerberich, Division of
Environmental and
Occupational Health, School
of Public Health, University
of Minnesota, 420 Delaware
Street SE, MMC $807 \mathrm{Mayo,}$
Minneapolis, MN 55455,
USA
gerbe001@umn.edu

A random sample of 1600 farming operations was generated from each of the five states, using the United States Department of Agriculture's (USDA) National Agricultural Statistics Service master sampling frame of farm operations. An introductory letter was sent to households of all farming operations by the USDA Agricultural Statistics Service offices indicating their strong support, and encouraging persons to participate. A letter from the investigators also included information on the purpose and importance of the project and provided informed consent, according to federal guidelines. Subsequently, specially trained interviewers conducted telephone interviews to determine whether the farming households on the list met the eligibility criteria. These included receiving $\$ 1000$ in revenue from agricultural products during the past year and whether they were actively farming during the study period. Eligible households were asked to participate in the project and were mailed information packets. These packets included an explanatory letter signed by the key investigators on letterhead that included the names of the investigators and representatives from the five states and a set of information cards to facilitate responses during the interviews. Comparable mailings, using the same procedures, were done before the initiation of the second six month interviews.

The female head of household was the preferred respondent for the demographic information and whether any family members were injured during the designated time frame; the male head of household was the preferred respondent for the farming operation exposure information. Injured persons were interviewed directly with the exception of those under 18, in which case the female head of household was the preferred respondent.

An injury was defined as a physiologic traumatic event that resulted in: restriction of normal activities for at least four hours; and/or the use of professional medical care; and/or loss of consciousness, loss of awareness, or amnesia for any length of time; or death. Injury data collected included type and severity of the injury together with the source, mechanism, and potential contributing factors. Both fatal and non-fatal injuries, classified either as intentional or unintentional, were included. ${ }^{5}$ To ascertain farming relatedness, the following question and explanation were provided: "Was the injury in any way related to your farm operation? This includes activities such as farm related transportation on roadways, or any other aspect of your farm, such as raising animals for recreation or home use".

Based on data from the OATS, ${ }^{318}$ that served as the foundation for the RRIS- $\mathrm{I}^{5}$ and involved validation of self reported injury, it would be expected that only minor injury events would have been missed. Through the OATS, self reports of injury were validated, using the gold standard of health care records maintained for virtually all residents in Olmsted County. ${ }^{19}$ From this validation effort, it was also possible to examine different interviewing strategies. The initial injury validation effort indicated an increase in the percentage of false negatives with an increase in the length of time between the injury event and the interview, particularly after six months. ${ }^{18}$ As well, there was a greater number of false negatives when the male head of household provided initial screening information on persons injured. As a result of the analysis, two major changes were implemented in RRIS-I: shortening the time between reported injury events and the interviews (from one year to six months) and increased efforts to have the female head of the household provide initial screening information. The techniques used to collect general exposure data were similar in both studies.

In addition to rates per 100000 population at risk, rate ratios with $95 \%$ confidence intervals were calculated using logistic regression. These included sociodemographic variables (state in the region, age, and gender), number of hours worked in farming operation related activities, size of farm, general environmental exposures, including the presence of animals and machinery in active use on the farm, and specific exposures involving animals, machinery, and chemicals, etc. Information on hours worked and certain specific farming operation related exposures, was collected only for those 5-19 years of age. Children under 5 were considered to have no exposure to specific farmwork activities involving operation of equipment and handling of chemicals; however, data were collected on this age group relevant to riding on a tractor and working with dairy cattle, beef cattle, or swine.

For the multivariate analyses, two models were developed. The first, based on a conceptual model of hypothesized risk factors/ exposures, was an a priori model, and involved sequential entry of variables in a logistic regression analysis. The order of variables entered ranged from most to least important and most amenable to intervention as follows: (1) hours worked per week; (2) whether they operated or worked with specific equipment and the total number of various types of equipment to which they were exposed; (3) state of residence and size of the farm; and (4) gender and age. A subsequent analysis, using backward stepwise logistic regression, was conducted to examine the relative merit of this model.

\section{Results}

The population of 3939 farm households that participated in the RRIS-I ${ }^{5}$ included data on 13144 persons (participation rate: 74\% among known eligible farms) Children and youth, aged $0-19$, accounted for $33 \%$ of this population. As shown in table 1, 381 experienced a total of 419 injury events, accounting for rates of 8663 and 9527 per 100000 persons, respectively. Injury rates for persons injured from farming and non-farming sources, respectively, were 1683 and 6980 per 100000 persons; the respective rates for injury events, including multiple events per person, were 1751 and 7776 . No deaths or intentional injuries were identified in this population. 
Table 1 Farming and non-farming operation related injury rates for persons and events per 100000 persons. Injuries among children in farm households: Regional Rural Injury Study-I

\begin{tabular}{|c|c|c|c|c|c|}
\hline & $\begin{array}{l}\text { Total population } \\
\text { at risk }\end{array}$ & $\begin{array}{l}\text { No of injured } \\
\text { persons }\end{array}$ & $\begin{array}{l}\text { No of injury } \\
\text { events }\end{array}$ & $\begin{array}{l}\text { Injured persons } \\
\text { per } 100000 \\
\text { population at } \\
\text { risk }\end{array}$ & $\begin{array}{l}\text { Injury events } \\
\text { per } 100 \text { 000 } \\
\text { population at } \\
\text { risk }\end{array}$ \\
\hline Farming related & 4398 & 74 & 77 & 1683 & 1751 \\
\hline Non-farming related & 4398 & 307 & 342 & 6980 & 7776 \\
\hline Total & 4398 & 381 & 419 & 8663 & 9527 \\
\hline
\end{tabular}

CHARACTERISTICS AND CONSEQUENCES OF THE INJURY EVENTS

There were a total of 77 farming related injuries. The main types of injuries were contusions (22\%), lacerations (21\%), and fractures (20\%) involving legs/knees/ankles (29\%), hands/fingers (23\%), and face/eyes/dental (16\%). The 342 non-farming related injuries were fractures (24\%), lacerations (22\%), and sprains/strains (22\%). The major body sites involved were legs/knees/ankles (29\%) and face/eyes/dental (16\%), comparable to those identified for farming related injuries; in addition, $22 \%$ involved shoulders/arms.

As shown in table 2, three major sources accounted for $66 \%$ of farming related injuries: animals; motor vehicles, such as trucks and four wheelers; and non-tractor farm machinery. The principal activities associated with these injuries (not shown in the table) were: (1) animal care $(47 \%)$, that included herding, cleaning, feeding, and milking; (2) riding in or on vehicles $(12 \%)$; (3) general farmwork (34\%), including fieldwork and fencing; and (4) horseplay, or being a bystander, in the realm of farming operation activities (8\%). For non-farming related injuries, $87 \%$ were associated with sports and recreational sources $(61 \%)$, surfaces involving falls (15\%), and motor vehicles (11\%). The main activities in which the children and youth were engaged at the time of these injury events were: (1) sports (45\%); (2) recreational activities (20\%); (3) vehicle operation (10\%); (4) non-farming work related activities ( $5 \%$ ); (5) other general physical activity (11\%); and (6) other general activity $(8 \%)$.

Several variables were used as proxies for measuring severity: hospitalization, medical treatment, duration of normal activity restriction, and persistent problems. Although only $3 \%$ of the farming related injury cases were hospitalized, $83 \%$ required some type of health

Table 2 Farming and non-farming operation related injuries by source of injury. Injuries among children in farm households: Regional Rural Injury Study-I; values are number (\%)

\begin{tabular}{llll}
\hline Source & $\begin{array}{l}\text { Farming operation } \\
\text { related events }\end{array}$ & $\begin{array}{l}\text { Non-farming operation } \\
\text { related events }\end{array}$ & Total \\
\hline Sports/recreation & - & $208(60.8)$ & $208(49.6)$ \\
Animals & $31(40.3)$ & $12(3.5)$ & $43(10.3)$ \\
Motor vehicles & $11(14.3)$ & $38(11.1)$ & $49(11.7)$ \\
Surface (falls) & $6(7.8)$ & $50(14.6)$ & $56(13.4)$ \\
Machine/equipment & $9(11.7)$ & $4(1.2)$ & $13(3.1)$ \\
Small power equipment & $6(7.8)$ & $5(1.5)$ & $11(2.6)$ \\
General work & $5(6.5)$ & $19(5.5)$ & $24(5.7)$ \\
Tractor & $4(5.2)$ & - & $4(0.9)$ \\
Storage structure & $3(3.9)$ & - & $2(0.7)$ \\
Chemicals & $2(2.6)$ & $3(0.9)$ & $3(0.7)$ \\
Housework & - & $3(0.9)$ & $3(0.7)$ \\
Other & - & $342(100.0)$ & $419\left(99.9^{\star}\right)$ \\
Total & $77\left(100.1^{\star}\right)$ & & \\
\hline
\end{tabular}

^Rounding error. care. Among those, $23 \%$ had no insurance and $57 \%$ had insurance that covered at least $50 \%$ of the costs. For non-farming related injury cases, $9 \%$ were hospitalized and $90 \%$ received medical care; $21 \%$ of these had no insurance and $59 \%$ had insurance that covered at least $50 \%$ of the costs.

A further indication of severity was the duration of restriction of a person's normal activity. Although $8 \%$ of the farming related injury cases had no restriction, $58 \%$ were restricted less than one week, $17 \%$ were restricted between one week to less than one month, and $17 \%$ were specifically restricted for one month to less than three months. Injuries involving one month or more of restriction were primarily associated with animals (54\%), followed by machinery $(23 \%)$. For nonfarming related injuries, $18 \%$ were restricted between one and three months and $6 \%$ for three months or more. Injuries associated with one month or more of restriction were due to sports and recreation (67\%), followed by falls $(15 \%)$, and motor vehicles (13\%). A final indicator of injury consequences and severity was whether those who were injured had persistent problems, including permanent disabilities. This involved $5 \%$ of the farming related injury cases and $13 \%$ of the non-farming related cases.

UNIVARIATE AND MULTIVARIATE ANALYSES OF EXPOSURES AND FARMING OPERATION RELATED INJURIES

Several variables, pertinent only to farming operation related injuries, were examined through both univariate and multivariate analyses. These included sociodemographic variables and both specific and general exposures. To determine specific exposures to farming operations, we asked about whether the children and youth, ages $0-19$, rode on a tractor or worked with dairy cattle, beef cattle, or swine. In addition, we asked whether those 5-19 years of age operated or worked with specific equipment (tractors, balers, augers, and harvesters) or chemicals, and the hours worked per week in farming operation related activities. Those younger than 5 were considered to have no exposure to these activities. The total number of exposed persons 5 or older and for whom all data were available was 3296 of the 4013 under 20 years of age. In a separate analysis, comparing these two populations, no important differences in rate ratios were observed.

Based on the unadjusted univariate analyses, shown in table 3, there were several increased rate ratios. As described in the methods section, multivariate analyses were also conducted, using logistic regression with an a priori model. This model involved sequential entry of the variables, progressing in an order hypothesized as the most important and most amenable to potential intervention to those least important and amenable. A subsequent analysis, using backward stepwise logistic regression, was conducted to examine the merit of this model. 
Table 3 Univariate and multivariate logistic regression analyses of farming related exposures. Injuries among children in farm households: Regional Rural Injury Study-I

\begin{tabular}{|c|c|c|c|c|c|c|c|}
\hline \multirow[b]{2}{*}{ Variable } & \multirow{2}{*}{$\begin{array}{l}\text { Total } \\
\text { exposed }\end{array}$} & \multicolumn{2}{|c|}{ Unadjusted } & A prio & nodel & Backz & stepwise model \\
\hline & & $R R$ & $95 \% C I$ & $R R$ & $95 \% C I$ & $R R$ & $95 \% C I$ \\
\hline Work on farm (ho & & & & & & & \\
\hline $0-9^{\star}$ & 2794 & 1.00 & - & 1.00 & - & & \\
\hline $10-19$ & 686 & 3.25 & 1.74 to 6.05 & 0.96 & 0.57 to 1.60 & & \\
\hline $20-29$ & 301 & 5.44 & 2.73 to 10.85 & 1.18 & 0.67 to 2.07 & & \\
\hline $30-39$ & 124 & 5.06 & 1.89 to 13.55 & 0.92 & 0.41 to 2.09 & & \\
\hline $40+$ & 108 & 7.09 & 2.82 to 17.78 & 1.59 & 0.73 to 3.48 & & \\
\hline Operate a tractor & & & & & & & \\
\hline $\mathrm{No}^{\star}$ & 2631 & 1.00 & - & 1.00 & - & 1.00 & - \\
\hline Yes & 1382 & 4.39 & 2.58 to 7.47 & 1.26 & 0.80 to 1.99 & 1.42 & 1.04 to 1.94 \\
\hline Ride a tractor? & & & & & & & \\
\hline No & 1405 & 1.00 & - & 1.00 & - & & \\
\hline Yes & 2608 & 2.68 & 1.40 to 5.14 & 1.17 & 0.82 to 1.66 & & \\
\hline Work with dairy & & & & & & & \\
\hline No & 3153 & 1.00 & - & 1.00 & - & 1.00 & - \\
\hline Yes & 860 & 3.43 & 2.10 to 5.61 & 1.70 & 1.20 to 2.40 & 1.60 & 1.19 to 2.14 \\
\hline Work with beef ce & & & & & & & \\
\hline No & 2795 & 1.00 & - & 1.00 & - & 1.00 & - \\
\hline Yes & 1218 & 2.40 & 1.47 to 3.93 & 1.17 & 0.87 to 1.56 & 1.22 & 0.94 to 1.59 \\
\hline Work with swine? & & & & & & & \\
\hline No & 3347 & 1.00 & - & 1.00 & - & & \\
\hline Yes & 666 & 1.95 & 1.13 to 3.38 & 1.10 & 0.81 to 1.50 & & \\
\hline Handle chemicals & & & & & & & \\
\hline $\mathrm{No}^{\star}$ & 3858 & 1.00 & - & 1.00 & - & & \\
\hline Yes & 155 & 3.10 & 1.39 to 6.91 & 1.06 & 0.68 to 1.68 & & \\
\hline Operate a harvest & & & & & & & \\
\hline $\mathrm{No}^{\star}$ & 3777 & 1.00 & - & 1.00 & - & 1.00 & - \\
\hline Yes & 236 & 5.53 & 3.10 to 9.89 & 1.30 & 0.86 to 1.96 & 1.37 & 0.98 to 1.91 \\
\hline Operate an auger & & & & & & & \\
\hline $\mathrm{No}^{\star}$ & 3267 & 1.00 & - & 1.00 & - & & \\
\hline Yes & 746 & 4.12 & 2.52 to 6.75 & 0.98 & 0.67 to 1.45 & & \\
\hline Operate a baler? & & & & & & & \\
\hline $\mathrm{No}^{\star}$ & 3441 & 1.00 & - & 1.00 & - & & \\
\hline Yes & 572 & 4.44 & 2.69 to 7.33 & 1.10 & 0.75 to 1.61 & & \\
\hline Any sheep on farr & & & & & & & \\
\hline No & 3544 & 1.00 & - & 1.00 & - & 1.00 & - \\
\hline Yes & 469 & 0.36 & 0.11 to 1.16 & 0.58 & 0.31 to 1.06 & 0.57 & 0.32 to 1.03 \\
\hline Any poultry on fa & & & & & & & \\
\hline No & 3480 & 1.00 & - & 1.00 & - & & \\
\hline Yes & 533 & 1.49 & 0.79 to 2.81 & 1.16 & 0.81 to 1.66 & & \\
\hline Any horses on far & & & & & & & \\
\hline No & 3052 & 1.00 & - & 1.00 & - & & \\
\hline Yes & 961 & 1.13 & 0.65 to 1.97 & 1.12 & 0.82 to 1.53 & & \\
\hline Any other livestoc & & & & & & & \\
\hline No & 3821 & 1.00 & - & 1.00 & - & & \\
\hline Yes & 192 & 0.63 & 0.15 to 2.59 & 0.76 & 0.36 to 1.61 & & \\
\hline No of types of eq & & & & & & & \\
\hline $1-10$ & 1724 & 1.00 & - & 1.00 & - & 1.00 & - \\
\hline $11-15$ & 1682 & 0.83 & 0.47 to 1.47 & 0.72 & 0.50 to 1.04 & 0.74 & 0.52 to 1.05 \\
\hline $16+$ & 607 & 1.70 & 0.91 to 3.18 & 0.94 & 0.60 to 1.46 & 0.99 & 0.65 to 1.50 \\
\hline Any all terrain vel & & & & & & & \\
\hline No & 2275 & 1.00 & - & 1.00 & - & 1.00 & - \\
\hline Yes & 1738 & 1.64 & 1.00 to 2.68 & 1.21 & 0.93 to 1.58 & 1.23 & 0.96 to 1.59 \\
\hline Any snowmobiles & & & & & & & \\
\hline No & 2834 & 1.00 & - & 1.00 & - & & \\
\hline Yes & 1179 & 1.62 & 0.98 to 2.67 & 1.20 & 0.90 to 1.60 & & \\
\hline Any motorcycles? & & & & & & & \\
\hline No & 2944 & 1.00 & - & 1.00 & - & & \\
\hline Yes & 1069 & 1.14 & 0.66 to 1.95 & 0.99 & 0.75 to 1.32 & & \\
\hline Any guns? & & & & & & & \\
\hline No & 491 & 1.00 & - & 1.00 & - & & \\
\hline Yes & 3522 & 1.68 & 0.67 to 4.22 & 1.11 & 0.69 to 1.80 & & \\
\hline State of residence & & & & & & & \\
\hline North Dakota & 750 & 1.00 & - & 1.00 & - & & \\
\hline Nebraska & 756 & 1.29 & 0.56 to 2.97 & 1.41 & 0.80 to 2.51 & & \\
\hline Wisconsin & 785 & 1.25 & 0.54 to 2.86 & 0.59 & 0.31 to 1.13 & & \\
\hline South Dakota & 827 & 1.09 & 0.47 to 2.54 & 1.23 & 0.70 to 2.16 & & \\
\hline Minnesota & 895 & 1.43 & 0.65 to 3.15 & 0.93 & 0.53 to 1.61 & & \\
\hline Acres in active pro & & & & & & & \\
\hline$<300$ & 1387 & 1.00 & - & 1.00 & - & & \\
\hline $300-599$ & 867 & 1.14 & 0.61 to 2.13 & 1.55 & 0.86 to 2.82 & & \\
\hline 600-999 & 632 & 1.10 & 0.55 to 2.21 & 1.54 & 0.82 to 2.87 & & \\
\hline $1000-1299$ & 371 & 0.31 & 0.07 to 1.31 & 2.91 & 0.85 to 9.91 & & \\
\hline $1300-1599$ & 147 & 0.78 & 0.18 to 3.35 & 1.05 & 0.30 to 3.63 & & \\
\hline $1600+$ & 609 & 0.76 & 0.34 to 1.69 & 1.13 & 0.54 to 2.37 & & \\
\hline Gender & & & & & & & \\
\hline Female & 1885 & 1.00 & - & 1.00 & - & 1.00 & - \\
\hline Male & 2128 & 4.44 & 2.31 to 8.51 & 1.47 & 1.02 to 2.13 & 1.63 & 1.15 to 2.30 \\
\hline Age group & & & & & & & \\
\hline $0-4$ & 717 & 1.00 & - & 1.00 & - & & \\
\hline $5-9$ & 996 & 0.54 & 0.19 to 1.55 & 0.65 & 0.32 to 1.32 & & \\
\hline $10-14$ & 1167 & 1.94 & 0.87 to 4.32 & 1.04 & 0.63 to 1.73 & & \\
\hline 15-19 & 1133 & 2.08 & 0.94 to 4.62 & 0.74 & 0.39 to 1.41 & & \\
\hline
\end{tabular}

${ }^{\star}$ Children $0-4$ years were set to this value.

$\mathrm{RR}=$ rate ratio; $\mathrm{CI}=$ confidence interval. 
Based on the results of analyses from these models (table 3), which were similar, increased rate ratios were related to working with dairy cattle as well as being male, whereas operating a tractor was important only in the backward stepwise model.

\section{Discussion}

This study, conducted in a five state region in the Midwest United States, is one of the most comprehensive to address injuries among children and youth in farm households. One limitation is the potential for recall bias. Although this bias cannot be discounted, the OATS $^{3}$ experience was used to modify pertinent data collection procedures in RRIS- $\mathrm{I}^{5}$ to minimize false negative reports and to enhance quality of reporting by using two six month reporting periods as well as to designate the female head of household as the preferred respondent for the demographic and injury information. Others support the finding that mothers respond more accurately than fathers about their children's injury experiences. ${ }^{20}$ While those researchers used two recall periods (the previous year and "ever") for health care visits, thus differing from our study, they also noted that parents' reports, compared with pediatricians' reports, may be a better source for some health events such as injuries. ${ }^{20}$

A similar finding, relevant to the importance of the six month recall, was also verified in another validation study that assessed a three year recall of self reported injury. In that study, self reporting was determined to be adequate for injury event enumeration for a maximum of six months. ${ }^{21}$

We found that only $3 \%$ of the farming related injury cases and $9 \%$ of the non-farming related injury cases were hospitalized. Yet, of the farming and non-farming related injuries, $83 \%$ and $90 \%$, respectively, required professional medical care and $34 \%$ and $42 \%$, respectively, were restricted from regular activity for one week or more. This finding, comparable to those identified for all injuries, both in the OATS $^{3}$ and RRIS- $\mathrm{I}^{5}$ studies, and by Brison and Pickett, ${ }^{22}{ }^{23}$ has implications for using hospital based surveillance systems exclusively. Only a small proportion of significant injuries can be detected through such systems.

Although the number of farming related injuries in this population was small, there were enough to enable identification of important risk factors. It is possible, however, that larger numbers could enable identification of additional factors.

The multivariate analyses showed that being male, working with dairy cattle, and operating a tractor, resulted in important increased injury rate ratios. This should prompt serious concerns about the occupational injury problem and extensive hazardous exposures experienced by this population. The age appropriateness of the tasks and equipment to which the children and youth are exposed ${ }^{24} 25$ appears integral to this problem. Child labor laws in the United States prohibit extremely hazardous jobs, for example, the operation of a tractor
Key points

- Injury rates: 1751 and 7776 injury events per 100000 persons for farming and nonfarming related activities, respectively.

- Sources/vehicles of injuries: animals $(40 \%)$ were the primary source of farming related injuries; sports/recreational sources $(61 \%)$ were primarily associated with non-farming injuries.

- Severity: $17 \%$ of farming related injury cases and $24 \%$ of non-farming related injury cases were restricted from regular activity for one month or more.

- Potential risk factors: through multivariate analyses, based on a conceptual model, increased rate ratios were identified for operating a tractor, working with dairy cattle, and being male.

with greater than 20 horsepower. However, a major exception to this legislation is provided for children and youth who work on their families' farms.

The risk of children and youth incurring a non-farming related injury, compared with a farming related injury, was four times greater. Although injuries were more severe as a result of non-farming related injury incidents, based on the proxies used, farming related injuries were also very important. The fact that children are experiencing any farming related injuries is important.

\section{Implications for prevention}

Our findings provide a foundation for additional analytic studies (for example, casecontrol studies) that will enable further identification of specific risk factors and, thereby, serve as a basis for development of relevant prevention and control strategies. In the meantime, given the current study findings pertinent to potential risk factors for farming related injuries, the North American Guidelines for Children's Agricultural Tasks should be considered for application. ${ }^{26}$ These guidelines, currently under evaluation, were developed to assist adults in assigning farm jobs to children 7-16 years of age who live or work on farms and include information on adult responsibilities, recommended level of supervision, child assessment (physical, mental, and emotional abilities), and main hazards (for example, animal care, tractor fundamentals, manual labor, general activities). Special versions available for professionals such as educators, youth safety specialists, and health care workers include a job hazard analysis framework and a child development checklist for 62 different jobs. In light of the complex interventions needed for this major public health problem, further evaluation remains critical to ensure the efficacy and long term success of these efforts.

Support, in part, was provided by: the Regional Injury Prevention Research Center, Division of Environmental and Occupational Health, School of Public Health, University of Minnesota, Minneapolis, Minnesota; the Occupational Injury 
Epidemiology and Control Program, Midwest Center for Occupational Health and Safety, Division of Environmental and Occupational Health, School of Public Health, University of Minnesota, Minneapolis, Minnesota; the Minnesota Center for Research in Agricultural Safety and Health, University of Minnesota, Minneapolis, Minnesota; the Centers for Disease Control, Division of Injury Epidemiology and Control, Center for Environmental Health and Injury Control (currently, National Center for Injury Prevention and Control); and the Academic Computing Services, University of Minnesota, Minneapolis, Minnesota. The authors also acknowledge Beth Johnson and Melinda Rambel who contributed, in part, to a comprehensive literature review for this effort.

1 Elkington JM. A case-control study of farmwork related injuries in Olmsted County, Minnesota. [Doctoral thesis.] Minneapolis: University of Minnesota, 1990.

2 Layde PM. Beyond surveillance: methodologic consideraMed 1990;18:193-200.

3 Gerberich SG, Gibson RW, Gunderson PD, et al. The Olmsted Agricultural Trauma Study (OATS): a population-based effort. Report to the Centers for Disease Control. Atlanta: CDfort. Repor 1991.

4 Gerberich SG, Gibson RW, Gunderson PD, et al. Surveillance of injuries in agriculture. Proceedings: Surgeon General's Conference on Agricultural Health and Safety. Cincinnati: National Insti
Health, September 1992.

5 Gerberich SG, Gibson RW, French LD, et al. The Regional Rural Injury Study-I (RRIS-I): a population-based effort. A Report to the Centers for Disease Control. Atlanta: CDC, 1993.

6 Gerberich SG, Gibson RW, Gunderson PD, et al. Regional Rural Injury Study (RRIS): a population-based effort. In: McDuffie HH, Dosman JA, Semchuk KM, et al, eds. Human sustenability in agriculture: health, safety, environment. Proceedings: Third International Symposium: Issues in Health, Safety and Agriculture. Saskatoon, Canada (May 1992), 1995

7 Gerberich SG. Prevention of death and disability in farming. In: McDuffie HH, Dosman JA, Semchuk KM, et al, eds. Human sustenability in agriculture: health, safety, al, eds. Human sustenability in agriculture: health, safety, environment. Proceedings: Third International Symposium: Issues in Health, Safey
(May 1992), 1995.

8 Gerberich SG, Gibson RW, Olson D. Rural penetrating trauma. In: Ivatury RR, Cayten CG, eds. Textbook of penetrating trauma. Philadelphia: Williams and Wilkins, 1996.

9 National Safety Council. (NSC). Accident facts. Chicago: National Safety Council, 1999
10 Aherin RA, Riesenberg L. 1978 Minnesota Farm Accident Survey (technical bulletin). Minneapolis: University of Minnesota, Agricultural Extension Service, 1979.

11 Gunderson PD, Gerberich SG, Gibson RW, et al. An analysis of variables potentially associated with trauma in the agricultural community. Proceedings: First World Conference on Accident and Injury Prevention. Stockholm, Sweden, September, 1989.

12 Gunderson PD, Gerberich SG, Gibson RW, et al. Injury surveillance in agriculture. Am f Ind Med 1990;18:169-78.

13 Rivara FP. Fatal and non-fatal farm injuries to children and adolescents in the United States, 1990-93. Inj Prev 1997:3. $190-4$.

14 Stallones L. Fatal unintentional injuries among Kentucky farm children: 1979 to 1985 . F Rural Health 1989;5:24656.

15 Stallones L. Surveillance of fatal and non-fatal injuries in Kentucky. Am F Ind Med 1990;18:223-34.

16 Gerberich SG, Gibson RW, French LR, et al. A populationbased study of machinery-related injuries: Regional Rural Injury Study-I (RRIS-I). Accid Anal Prev 1998;30:793804.

17 Lee T-Y, Gerberich SG, Gibson RW, et al. A populationbased study of tractor-related injuries: Regional Rural Injury Study-I (RRIS-I) f Occup Environ Med 1996:38: $782-93$.

18 Gerberich SG, Gibson RW, Gunderson PW, et al. Validity of trauma reporting in the agricultural community. $\mathcal{F}$ Occup Acc 1990;12:200.

19 Melton LJ III. History of the Rochester Epidemiology Project. Mayo Clin Proc 1996;71:266-74.

20 Pless CE, Pless IB. How well they remember: the accuracy of parent reports. Arch Pediatr Adolesc Med 1995;149:553-

1 Braun BL, Gerberich SG, Sidney S. Injury events: utility of self-report in retrospective identification in the USA. $\mathcal{F}$ Ep $i$ demiol Community Health 1994;49:604-5.

22 Brison RJ, Pickett CWL. Non-fatal farm injuries on 117 Eastern Ontario beef and dairy farms: a one year study. Am F Ind Med 1992;21:623-36.

23 Brison RJ, Pickett CWL. Nonfatal farm injuries on eastern Ontario: a retrospective survey. Accid Anal Prev 1991;23: 585-94.

24 Swanson JA, Sach MI, Dahlgren KA, et al. Accidental farm injuries in children. Am $\mathcal{F}$ Dis Child 1997;141:1276-9.

25 National Committee for Childhood Agricultural Injury Prevention (NCCAIP). Children and agriculture: opportunities for safety and health. Marshfield, Wisconsin: Marshfield Clinic, 1996.

26 National Children's Center for Rural and Agricultural Health and Safety. North American guidelines for children's agricultural tasks (NAGCAT). Marshfield, WI: 1999. 